\title{
Quantitative Analysis of Domestic Logistics Outsourcing Research Literature Based on CiteSpace
}

\author{
Daoju Wei, Peijian Wu* \\ School of Business Administration, Anhui University of Finance and Economics, Bengbu, China \\ Email: *wupeijian@126.com
}

How to cite this paper: Wei, D.J. and $\mathrm{Wu}$, P.J. (2020) Quantitative Analysis of Domestic Logistics Outsourcing Research Literature Based on CiteSpace. Open Access Library Journal, 7: e6972.

https://doi.org/10.4236/oalib.1106972

Received: November 9, 2020

Accepted: December 19, 2020

Published: December 22, 2020

Copyright (c) 2020 by author(s) and Open Access Library Inc.

This work is licensed under the Creative Commons Attribution International License (CC BY 4.0).

http://creativecommons.org/licenses/by/4.0/

\begin{abstract}
This paper uses CiteSpace software to conduct a quantitative analysis of 366 kinds of literature on logistics outsourcing from 2000 to 2019 in the CNKI database, identify the research status and hotspots of logistics outsourcing in China and then summarize the deficiencies and future research directions. The paper identifies the research status of logistics outsourcing in China through the analysis of authors and research institutions. There are many scholars doing research, but the number of published papers is not very high, and the research institutions are mainly colleges and universities. Through literature analysis of co-occurrence keywords simultaneously, identifying the hot topics in the study of China's logistics outsourcing, logistics outsourcing risk, and cost has always been a burning problem in the survey on logistics outsourcing in China. With the constant rise of the supply chain and the development of logistics, logistics outsourcing decision-making, logistics outsourcing performance, and relationship quality are becoming a research hotspot in logistics outsourcing. We can consider the version of logistics outsourcing, logistics outsourcing based on the supply chain, and logistics outsourcing's collaborative research in future.
\end{abstract}

\section{Subject Areas}

Logistics Outsourcing

\section{Keywords}

Logistics Outsourcing, CiteSpace, Co-Occurrence Analysis

\section{Introduction}

With the rapid development of the social economy and market competition in- 
tensifying, how to reduce logistics costs, improve service quality, and focus on core competitiveness has become the urgent demand for enterprise development. More and more companies choose to give up their logistics through the logistics outsourcing business cooperation with a professional logistics company; the scale of the third-party logistics market is becoming bigger and bigger. In 2010, the size of China's third-party logistics market was about 649.9 billion yuan. By 2017, China's third-party logistics market has grown to 1241.1 billion yuan, and according to the forecast, the size of China's third-party logistics market will reach 1.6 trillion yuan by 2020 [1]. Simultaneously, the country attaches more and more critical to the logistics industry's high-quality development, and the environment and service quality of logistics development are also continually developing and improving. On February 26, 2019, several departments of the State Council jointly issued the Opinions on Promoting the Development of High-quality Logistics and Promoting the Formation of a Strong Domestic Market. We can believe that with the improvement of logistics service quality, more and more enterprises will choose logistics outsourcing.

Domestic research on logistics outsourcing has only been paid attention to by scholars since 2000. Scholars have studied logistics outsourcing mainly from many aspects, such as logistics outsourcing performance, logistics service provider selection, logistics outsourcing risk, and outsourcing cost. Yuanxu Li [2] discussed virtual enterprises' logistics problems. He thought that virtual enterprises should outsource the logistics business in 2000. Ying Feng [3], Maosheng Yang [4], Yabing Li [5], Shasha Xiang [6], Xiang Li [7], and Xiaohong Zeng [8] researched logistics outsourcing risk based on different types of enterprises or other methods; Zhixue Liu [9], Shuyun Wang [10], and Xiaoqun Liu [11] studied the outsourcing cost and cost measurement of logistics. Xiong Wang [12] and Liqin Liu [13] used different methods for analyzing logistics service providers' choice. Yu Tian [14], Yang Cao [15], Xiaobo Sun [16] studied the outsourcing relationship and its existing trust and risk issues. The current research on logistics outsourcing pays little attention to the performance of logistics outsourcing. The risk control and benefit distribution of logistics outsourcing based on the supply chain environment are not very involved. Also, there are no relatively stable research teams and less cooperation among research institutions.

In this paper, we will determine the scope of research in China. Compared with the foreign research results in the same period, the number of domestic research results is similar, using the database of Web of Science to search 430 foreign papers at the same time. Therefore, we hope to understand the research subjects, research focus, and research progress of domestic logistics outsourcing through the study and then understand its research characteristics.

\section{Data Sources and Research Tools}

\subsection{Data Sources}

This paper's literature materials are selected from the journal databases in CNKI. 
The retrieval conditions were as follows: the keywords or article is "logistics outsourcing"; the source category is "Peking University Chinese core journals and CSSCI journals", because the database of CNKI is relatively complete and of high quality. Since the earliest articles on logistics outsourcing included in CNKI were published in 2000 , I select the literature publication time of the retrieval condition authors as "2000-2019". We retrieve a total of 377 pieces of literature. After excluding some irrelevant literature such as preface and description, we obtained 366 works of literature.

\subsection{Research Tools}

This paper's research tool is CiteSpace software developed by Professor Chaomei Chen of Drexel University. Since its introduction to China, CiteSpace software has been widely used in scientific papers, dissertations, and monographs to analyze and explore research hotspots, research frontiers, and research trends [17]. In this paper, CiteSpace software analyzes the authors, research institutions, and research progress in logistics outsourcing research to learn the characteristics and future development of domestic logistics outsourcing research in the past 20 years.

\section{The Domestic Logistics Outsourcing Research Subject Analyzing}

\subsection{Co-Occurrence Analysis of Domestic Logistics Outsourcing Research Authors}

We used CiteSpace software to analyze domestic logistics outsourcing research from 2000 to 2019 to understand the high-yielding authors and their cooperation. When we open CiteSpace software, Time Slicing selection from 2000 to 2019, Node Types selection Author, and Selection Criteria selection g-index. After running the software, Table 1 shows the authors in the research field of domestic logistics outsourcing.

Table 1. The top 10 authors in the field of logistics outsourcing research from 2000 to 2019.

\begin{tabular}{ccc}
\hline The serial number & The author & Number of posts \\
\hline 1 & Shuyun Wang & 9 \\
2 & Yande Gong & 7 \\
3 & Xiangru Meng & 6 \\
4 & Zhixue Liu & 6 \\
5 & Xiaoqun Liu & 5 \\
6 & Qingli Da & 5 \\
7 & Yanping Liu & 5 \\
8 & Benhong Peng & 4 \\
9 & Yijun Liu & 4 \\
10 & Haiping Wang & 4 \\
\hline
\end{tabular}


As can be seen from Table 1, many domestic scholars have conducted researches on logistics outsourcing. However, the publication volume is generally not very high, and several kinds of the literature of many scholars published in two or three years. As shown in Table 1, authors in the research field of logistics outsourcing are ranked in order by the number of published articles, such as Shuyun Wang, Yande Gong, Xiangru Meng, Zhixue Liu, Xiaoqun Liu, Qingli $\mathrm{Da}$, Yanping Liu. Among them, at most nine articles published by Shuyun Wang, the publication time is relatively concentrated. She published six of them in 2004 and the other three in 2003, 2006, and 2012. Yande Gong has posted a total of 7 papers. From the time of publication, his research on logistics outsourcing has been relatively continuous since 2008. From 2003 to 2012, Zhixue Liu has published papers successively. From 2008 to 2016, Qingli Da has published articles on logistics outsourcing intermittently, but he completed most of them in cooperation with others. Xiangru Meng published some writings from 2004 to 2008. Xiaoqun Liu mainly focuses on 2004, 2005, and 2006. Yanping Liu mainly concentrated in 2005, 2006, and 2009; Benhong Peng primarily published in 2007 and 2008. Yijun Liu focuses mostly on 2010, 2011, and 2012. Haiping Wang concentrates mainly on 2007, 2010, and 2012.

According to the software analysis, nearly half of the 366 journals in the retrieved logistics outsourcing research field were completed by the relevant authors alone regarding the author's cooperative relationship network. However, two or three authors published most of the papers, and more than three authors publish relatively few. Two or three authors jointly published reports for half of the total literature volume, while more than three authors published only 12 articles. The co-authors' cooperative relationship is not very close, and most do not form a relatively fixed team. Table 2 shows the author's publication in the field of logistics outsourcing research.

\subsection{Co-Occurrence Analysis of Domestic Logistics Outsourcing Research Institutions}

According to domestic research institutes in logistics outsourcing obtained from CiteSpace software's operation, ten research institutes or institutions have published more than four papers in this field. Table 3 shows the specific situation. Among them, the four institutions ranked in the top three published 13 essays

Table 2. Cooperation between authors in the field of logistics outsourcing Research.

\begin{tabular}{ccc}
\hline $\begin{array}{c}\text { Number of Authors } \\
\text { (person) }\end{array}$ & $\begin{array}{c}\text { Number of literature } \\
\text { (articles) }\end{array}$ & $\begin{array}{c}\text { Percentage of total } \\
\text { publications (\%) }\end{array}$ \\
\hline 1 & 171 & 47 \\
2 & 127 & 35 \\
3 & 56 & 3 \\
\hline
\end{tabular}


Table 3. Ranking of publication volume of research institutions.

\begin{tabular}{|c|c|c|}
\hline The serial number & Research institutions & Number of posts \\
\hline 1 & $\begin{array}{l}\text { School of Management, Huazhong University } \\
\text { of Science and Technology }\end{array}$ & 13 \\
\hline 2 & $\begin{array}{c}\text { School of Economics and Management, } \\
\text { Yantai University }\end{array}$ & 9 \\
\hline 3 & $\begin{array}{l}\text { School of Economics and Management, Nanjing } \\
\text { University of Aeronautics and Astronautics }\end{array}$ & 7 \\
\hline 4 & $\begin{array}{l}\text { School of Economics and Management, } \\
\text { Southeast University }\end{array}$ & 7 \\
\hline 5 & $\begin{array}{l}\text { School of Economics and Management, } \\
\text { East China Jiaotong University }\end{array}$ & 5 \\
\hline 6 & $\begin{array}{c}\text { School of Economics and Business Administration, } \\
\text { Chongqing University }\end{array}$ & 5 \\
\hline 7 & $\begin{array}{l}\text { School of Economics and Management, } \\
\text { Shanghai Institute of Technology }\end{array}$ & 4 \\
\hline 8 & $\begin{array}{l}\text { Department of Economic Management, } \\
\text { Hunan Institute of Engineering }\end{array}$ & 4 \\
\hline 9 & Wuxi College of Commerce and Technology & 4 \\
\hline 10 & Business School of Renmin University of China & 4 \\
\hline
\end{tabular}

by the School of Management of Huazhong University of Science and Technology, nine reports by the School of Economics and Management of Yantai University, seven papers by the School of Economics and Management of Nanjing University of Aeronautics and Astronautics and seven essays by the School of Economics and Management of Southeast University. Also, from the publishing institutions' region, there are six research institutions in east China in the top 10. They are Yantai University, Nanjing University of Aeronautics and Astronautics, Southeast University, East China Jiaotong University, Shanghai College of Applied Technology, and Wuxi College of Business and Vocational Technology. Two universities in central China: Huazhong University of Science and Technology and Hunan College of Engineering; one university in North China, Renmin University of China; Chongqing University in southwest China.

\section{Domestic Logistics Outsourcing Research Focuses on Analyzing}

\subsection{Keyword Frequency Analysis}

Keywords can reflect the main content of the article more intuitively. Understanding the research hot spots in a specific research field can be obtained by analyzing the keywords that frequently appear in this field's current research results. Therefore, a keyword frequency analysis of the contemporary literature in 
domestic logistics outsourcing research can help us understand the area's hot spots and directions.

In Table 4, there are keywords with a frequency greater than 10 in the research field of logistics outsourcing from 2000 to 2019, which reflect the research hotspots in the research field of logistics outsourcing. The frequency of logistics outsourcing of co-occurrence is 244 times. The frequency of third-party logistics is 58 times; outsourcing is 15 times, a supply chain is 16 times, the core competitiveness is 15 times, the core competence is 11 times. The research on logistics outsourcing mainly focuses on many aspects, such as logistics outsourcing, third-party logistics, business outsourcing. Meanwhile, it also focuses on logistics service providers and outsourcing risks. Besides, with the deepening of supply chain research, logistics outsourcing research also focuses on the supply chain, core competence, core competitiveness, and other content.

Table 4. Frequency ranking of keywords in logistics outsourcing research field.

\begin{tabular}{|c|c|c|}
\hline Ranking & Keywords & The co-occurrence frequency \\
\hline 1 & Logistics outsourcing & 244 \\
\hline 2 & Third-Party logistics & 58 \\
\hline 3 & Logistics & 28 \\
\hline 4 & Outsourcing & 25 \\
\hline 5 & Enterprise & 22 \\
\hline 6 & Logistics enterprises & 20 \\
\hline 7 & The enterprise management & 18 \\
\hline 8 & Manufacturing & 16 \\
\hline 9 & The logistics activity & 16 \\
\hline 10 & The supply chain & 16 \\
\hline 11 & Outsourcing & 15 \\
\hline 12 & Enterprise logistics & 15 \\
\hline 13 & Core competitiveness & 15 \\
\hline 14 & Logistics service & 12 \\
\hline 15 & Third-Party logistics enterprise & 12 \\
\hline 16 & Logistics service provider & 12 \\
\hline 17 & Risk & 12 \\
\hline 18 & Enterprise logistics outsourcing & 11 \\
\hline 19 & The logistics industry & 11 \\
\hline 20 & Core competence & 11 \\
\hline
\end{tabular}




\subsection{Keywords Paroxysmal Test}

A burst is when the value of a variable changes significantly one or more times in a short period. A subject mutation refers to the change of subject in a particular field, which causes attention changes in a short period with the occurrence of an event [18]. The purpose of the sudden test of keywords is to understand the difference and development of keywords and then understand the effect of related research in logistics outsourcing represented by keywords from 2000 to 2019.

Table 5 shows keywords with high intensity in the research field of logistics outsourcing from 2000 to 2019. From 2006 to 2013, logistics outsourcing research mainly focuses on the following aspects, such as logistics, business outsourcing, enterprise management, enterprise, core competence, logistics self-operation, and strategy. It primarily focused on core competitiveness, logistics industry, manufacturing industry, service outsourcing, and other contents. From 2013 to 2019, it mainly focused on the supply chain, logistics outsourcing performance, relationship quality, and other contents. From these keywords,

Table 5. Top 17 keywords with the strongest citation bursts.

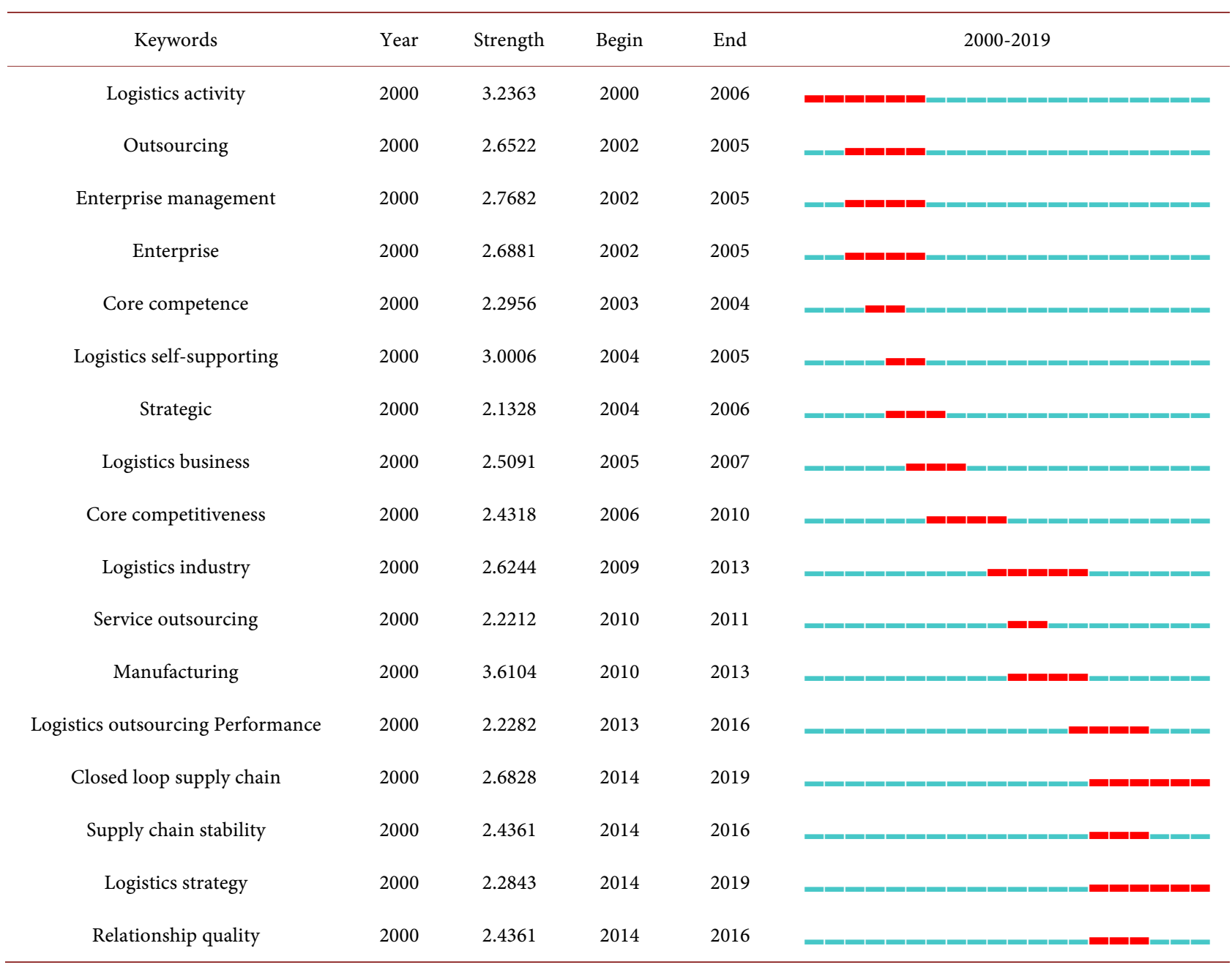


such as "enterprise management," "enterprise," "logistics industry," and "manufacturing industry," we can see that scholars pay attention to logistics outsourcing from the enterprise and industry level in the early stage of the study. "Core competence" and "core competitiveness" reflect the advantages of enterprises in choosing logistics outsourcing. With the development of supply chain management, the emergence of keywords such as "closed-loop supply chain," "supply chain stability," and "relationship quality" means that logistics outsourcing under the supply chain environment has become a new hot spot in logistics outsourcing research.

\section{Research Conclusion and Prospect}

\subsection{Research Conclusions}

This paper uses CiteSpace software to conduct a quantitative analysis of domestic literature related to logistics outsourcing in the past 20 years and finds that:

Firstly, from the perspective of research authors and institutions: On the author's side, more domestic scholars have begun to pay attention to logistics outsourcing research, but the general volume of publications is not very large; most of them have concentrated time of publication. Besides, the relevant scholars independently completed nearly half of the published literature articles. The articles' co-authors are mainly 2 - 3 people, and most do not form a relatively fixed team. In terms of research institutions, the research institutions engaged in logistics outsourcing in China are mainly some colleges and universities. There are not many high-yield institutions, and most of them conduct research independently. Besides, from the top research institutions' distribution region, they are mainly concentrated in south China's relevant universities.

Secondly, from the perspective of research hotspots, "logistics outsourcing" has always been the most significant focus of attention in the field of domestic logistics outsourcing research. In the early stage, it mainly introduced some fundamental theories, such as concepts and characteristics. Later, with the development of research, scholars have studied it from various perspectives, such as cost, performance, and risk. Besides, it is related to "supply chain," "core competitiveness," and "logistics service provider," such as the choice of the service provider, relationship quality, and other aspects.

Finally, from the research perspective, the overall domestic research on logistics outsourcing is not very high. The reason is mainly due to the increasing depth and refinement of examinations on logistics outsourcing by scholars. For example, the third-party logistics number for 1745 during this period, the logistics service provider's number is 209 , the risk of outsourcing number is 170 , the logistics alliance's number is 162 .

\subsection{Outlook}

Through the analysis of domestic logistics outsourcing research, we can see that China's logistics outsourcing research is continuing to deepen, among which 
there are still many problems worth in-depth discussion and analysis:

\subsubsection{Performance Research of Logistics Outsourcing}

At present, domestic scholars do not study the performance of logistics outsourcing very much. However, many factors are affecting the performance of logistics outsourcing. Therefore, scholars may consider establishing corresponding models through different methods to analyze logistics outsourcing in the future.

\subsubsection{Research on Logistics Outsourcing Based on the Supply Chain} With the continuous deepening of research on the supply chain, logistics outsourcing in the supply chain environment has increasingly attracted scholars and enterprises' attention. However, the current research mainly focuses on logistics outsourcing decision-making and other contents, and logistics outsourcing risk control and benefit distribution based on the supply chain will also focus on the future.

\subsubsection{Collaborative Research on Logistics Outsourcing}

There are relatively stable research teams and less cooperation among research institutions in logistics outsourcing in China. However, logistics outsourcing involves many fields. In the future, scholars may consider enhancing collaborative research between scholars and teams from different disciplines and backgrounds.

Besides, this paper's literature materials are mainly from the core Chinese journals of Peking University and the CSSCI journals of CNKI, without selecting other databases or the inclusion of the literature published by Chinese scholars in international journals in the research scope. With the development of the logistics industry and the acceleration of logistics research's internationalization, it is incredibly essential to make in-depth research and comparative analysis of logistics outsourcing and foreign databases.

\section{Fund Project}

Anhui Provincial Natural Science Research Project of Institutions of higher learning "Optimization Method of Enterprise Logistics Outsourcing Performance-oriented to Industrial Transfer-Empirical Research on the Demonstration Area of Undertaking Industrial Transfer in Wanjiang City Belt" (Subject No. KJ2011Z004).

\section{Conflicts of Interest}

The authors declare no conflicts of interest regarding the publication of this paper.

\section{References}

[1] Sun, L. and Zhang, Y.L. (2019) Development Status of Third Party Logistics. Consumer Guide, No. 11, 118.

[2] Li, Y.X. (2000) Research on Virtual Enterprise Logistics. Social Science, No. 1, 
21-24.

[3] Feng, Y. and Li, J. (2019) Research on Logistics Outsourcing Risk Control of Home Appliance Retailers Based on System Dynamics. Price Monthly, No. 4, 37-43

[4] Yang, M.S. and Li, Q.Y. (2007) Grey Cluster Correlation Evaluation of Logistics Outsourcing Risk Control. Market Modernization, No. 11, 113.

[5] Li, Y.B., Tao, J.B. and Qiao, P.L. (2018) Research Progress of Logistics Outsourcing Risk and Control for Manufacturing Enterprises. Business Times, No.12, 18-19.

[6] Xiang, S. and Xi, Y.F. (2009) Application of Grey Correlation Degree Analysis in Logistics Outsourcing Risk Control. Statistics and Decision-Making, No. 5, 169-170.

[7] Xiang, L. (2013) Risk Evaluation and Control of Enterprise Logistics Outsourcing-From the Perspective of the AHP-Fuzzy Comprehensive Evaluation Method. Enterprise Economics, No. 4, 72-75.

[8] Zeng, X.H. (2015) Some Logistics Outsourcing Risk Control Model and Method. Statistics and Decision-Making, No. 6, 165-168.

[9] Xu, J. and Liu, Z.X. (2007) Logistics Outsourcing Cost Risk Based on Real Option. Systems Engineering, No. 12, 30-33.

[10] Wang, S.Y. (2004) Determinants of Logistics Outsourcing Cost and Strategic Choice of enterprises. Economic Exploration, No. 7, 52-54.

[11] Liu, X.Q and Lai, Y.T. (2005) Research on the Measurement of Activity-based Logistics Outsourcing Cost. Auditing and Economic Research, No. 2, 54-58.

[12] Wang, X. (2008) Research on Semi-Structured Fuzzy Decision Making of Logistics Outsourcing Service Providers. Science and Technology Management Research, No. $1,131-133$.

[13] Liu, L.Q. (2013) Grey Multi-Level Evaluation and Selection of Logistics Service Providers Based on the Combinational Weight Method. Logistics Technology, No. 11, 318-321

[14] Tian, Y. and Yan, Q. (2007) Research on Influencing Factors of Trust of Demander of Logistics Service in Logistics Outsourcing Relationship. International Trade Issues, No. 5, 29-33.

[15] Cao, Y. (2014) Logistics Outsourcing Relationship and Risks Based on Principal-Agent Mechanism. Logistics Technology, No. 11, 118-120.

[16] Sun, X.B. and Luo, W.P. (2015) Analysis and Dynamic Comparison of Perceived Gap in Logistics Outsourcing Relationship. Journal of Xidian University of Science and Technology of Xi an (Social Science Edition), No. 9, 20-26.

[17] Li, J. and Chen, C.M. (2016) CiteSpace: Technology Text Mining and Visualization. The Capital University of Economics and Business Press, Beijing, 36.

[18] Li, Y., An, X.X. and Zhao, Y.G. (2013) Research on Emergent Topic Monitoring Combined with Knowledge Organization System. Information Theory and Practice, No. 5, 120-123. 